\title{
Simultaneous Diagnostic Assay of Catechol and Caffeine Using an in vivo Implanted Neuro Sensor
}

\author{
Suw Young Ly, Chang Hyun Lee, ${ }^{\dagger}$ Young Sam Jung,,${ }^{\ddagger}$ O Min Kwon, Ji Eun Lee, Seung Min Baek, and Kyu Ju Kwak

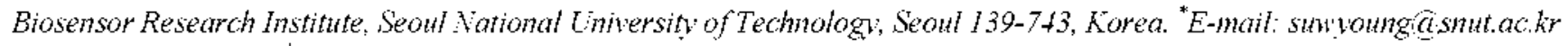 \\ ${ }^{\dagger}$ Division of Generd Edtcation, Pwongtaek Lniversitw, Gveonggi $450-701$, Korea \\ ${ }^{\ddagger}$ Department of Chemistry, Korea Lniversity, Seoul 136-701, Korea \\ sFod Science \& Technologu, Seoul National Lniversity of Technologv, Seoul 139-743, Korea \\ "Department of Chemistry Ionsei University, Seoul 120-749, Korea \\ Received Hay 19, 2007
}

\begin{abstract}
Catechol and caffeine were simultaneously analyzed with a bismuth-immobilized carbon nanotube paste electrode (BPE) using square wave (SW) stripping voltammetry. Optimum analytical conditions were determined. Simultaneous working ranges of $100-1.500 \mathrm{mgL}^{-1}$ for caffeine and $5-75 \mathrm{mgL}^{-1}$ for catechol were obtained. In the separated cell sy'stems. a working range of $0.1-2.1 \mathrm{mgL}^{-1}$ catechol with a correlation coefficient of 0.9935 . and a working range of $10-210 \mathrm{mgL}^{-1}$ caffeine with a correlation coefficient of 0.9921 were obtained. A detection limit $(\mathrm{S} / \mathrm{N})$ of $0.15 \mathrm{mgL}^{-1}\left(7.7 \times 10^{-7} \mathrm{M}\right)$ and a detection limit of $0.02 \mathrm{mgL}^{-1}(1.82 \times$ $10^{-7} \mathrm{M}$ ). respectively. manifested for catechol and caffeine. It was found that three macro-type electrode systems could be implanted in fish and rat neuro cells. For both ions. the ion currents were observed. The physsiological impulse conditions and the neuronal thinking current were also obtained.
\end{abstract}

Key Words : Catechol, Caffeine, Brain, Voltammetry

\section{Introduction}

Caffeine and ethanol are commonly used as psychoactive dietary components. ${ }^{1}$ clinical central stimulants. " diuretics and analgesics. and also for the treatment of brain disorders such as vascular headaches and Parkinson's disease. Moreover. catechol ions are related to various mental functions. behavior. ${ }^{4}$ breast cancer. schizophrenia. ${ }^{5}$ Parkinson's disease. and high blood pressure. ${ }^{6}$ Thus. in in-miro diagnosis. the traces of these assays are essential for the proper functioning of a body's central nervous sy'stem and for physiological control. Furthermore. the redox activities of these materials have been associated with several neurodegenerative disorders. For these reasons. in wivo direct assays are very important in treating neuroblastoma. heart failure. ${ }^{7}$ cancer. Parkinson and behavior controls. ${ }^{4-6}$

Various analytical methods that have low detection limits (DL) have been used for both ions. but all these methods were performed under laboratory conditions and are thus not usable in in vivo direct analysis. These methods are HPLC with the UV detection method (DL: $0.3 \mathrm{mgL}^{-1}$ caffeine) ${ }^{8}$ capillary zone electrophoresis (DL: $1.9 \mathrm{mgL}^{-1}$ caffeine), microchannel electrophoresis with the electrochemical detection method (DL: $4 \mathrm{uM}$ caffeine) ${ }^{16}$ solid-phase Fourier transform Raman spectrometry (DL: $18 \mathrm{mgL}^{-1}$ caffeine). ${ }^{11}$ high-performance liquid chromatography assay (DL: 0.3 $\mathrm{mgL}^{-1}$ caffeine). ${ }^{12}$ the capillary gas chromatography method. ${ }^{13}$ capillary electrochromatography. ${ }^{1+}$ GC and HPLC quantification. ${ }^{15}$ gas chromatography-ion trap tandem mass spectrometry. ${ }^{16}$ flow injection mass spectrometry. ${ }^{17}$ and the capillary high-performance liquid chromatography/electrospray mass spectrometry system. ${ }^{18}$ These techniques are applied only in in vitro conditions and are not applicable in in vivo direct assay. Moreover. catechol was studied in various analytical methods such as the capillary electrophoresis microchip with chemiluminescence method (DL: $100 \mathrm{uM}$ catechol) ${ }^{19}$ the voltanmetric conducting polymer electrode (DL: $10 \mathrm{ppb}$ catechol). ${ }^{21}$ the amperometric detectors for liquid cluromatographic method (DL: $1.5 \mathrm{uML}^{-1}$ catechol). ${ }^{21}$ and the electrochemical detectors in flow injection HPLC method (DL: $0.5 \mathrm{uML}^{-1}$ catechol). also applied only under laboratory conditions and required a complicated design. pre-treatment techniques. and expensive instruments. Moreover. these teclniques are not applicable in in vivo or tissue assay's. so simpler and lower-cost methods are needed. Voltanmmetric methods are inexpensive and useful for this purpose ${ }^{33.24}$ Related methods such as the anodic conductive diamond electrode ${ }^{25}$ the glass membrane $\mathrm{pH}$ electrode (DL: $0.6 \mathrm{mgL}^{-1}$ caffeine) - $^{26}$ and others are studied in terms of sensitive working ranges. but these are still not applicable in in vino direct assay. This study was first carried out for an in-vino direct assay with an implanted BPE (bismuth-inmobilized carbon nanotube paste electrode). The BPE sensor was prepared by using a graphite carbon nanotube $(\mathrm{CN})$. which is usable in electrode sensor systems owing to its mechanical and catalytic capabilities. ${ }^{27}$ Its $\mathrm{CN}$ powder was used with bismuth ${ }^{2 \mathrm{i}}$ inmmobilized on a carbon paste electrode. ${ }^{29}$ Optimum analytical conditions were obtained. and the sensor was found to be more sensitive than other common methods. The sensor was interfaced with an electrochemical workstation and the neuron of a fish brain or a rat brain to gain a neuronal current. Initially, the method can be applied in real-time live direct assay. It is also applicable to organ monitoring. in-vivo 
diagnosis, and other methods that require physiological interface control.

\section{Experimental Systems, Reagents, Electrodes, and Animals}

The analytical system used was the $\mathrm{CHI}$ electrochemical workstation 660A in Cordova, (CH Instruments, Inc.. Temuison. Austin, USA). The reagent-grade catechol (MW: $110.11 \mathrm{~g} / \mathrm{mol}$ ). caffeine (MW: $194.19 \mathrm{gmol}^{-1}$ ), bisnuth $\left(1,000 \mathrm{mgL}^{-1}\right)$ and other reagents were from Sigma. The carbon nanotubes, having an outside diameter of $8 \mathrm{~lm}$, an inside diameter of 2-5 nm. and a length of $0.5-200 \mathrm{~nm}$, from Nanostructured \& Amorphous Materials, Inc. were prepared overnight via catalytic CVD (metal-catalyzed chemical vapor deposition) prior to use by magnetic stirning in a $2 \mathrm{M}$ nitric acid solution. and then washed with pure water. The BPE working electrode was prepared with a paste composed of a mixed carbon nanotube and bismuth (standard) with a ratio of $4: 4.2$ by \% (w/w) in reagent-grade mineral oll (New Jersey, USA 1-800-01, Acro). The mixed paste was inserted into a plastic syrunge needle with a diameter of $2 \mathrm{~mm}$ and with a copper wire connected to the electric system. The $\mathrm{CN}$ electrode was made with a carbon nanotube and mineral oil at a ratio of $4: 2 \%(\mathrm{w} / \mathrm{w})$ with hand mixing. The glassy carbon electrodes were BAS stationary voltanmetric electrodes MF- 2012 with a $3.0-\mathrm{mm}$ diameter. The $\mathrm{Ag} / \mathrm{AgCl} / \mathrm{KCl}$ reference electrodes were prepared with a chloride-coated $0.2 \mathrm{~mm}$ silver wire. and a $0.2 \mathrm{~nm}$ platinun wire was used as the auxiliary electrode. A 120-gram fish and a 250-gram male rat from the authors' laboratory were used. An electrolyte solution of $0.1 \mathrm{M} \mathrm{H}_{3} \mathrm{PO}_{4}$ was prepared without removing the oxygen. All the expeniments were performed at room temperature.

\section{Results and Discussion}

Electrode Comparison by Voltammetry. In cyclic voltanmetry. analytical peak potential is determined using a high concentration of caffeine and catechol spiked with a glassy carbon electrode. Figure 1(a) shows the results. In the blank solution. no signal was obtained and thus. two ions were spiked at $10-20 \mathrm{mgL}^{-1}$. At the anodic scan, two oxidation peaks were obtained at $0.6 \mathrm{~V}$ (catechol) and $1.6 \mathrm{~V}$ (caffeine). As higher ranges were spiked from 30 to 80 $\mathrm{mgL}^{-1}$. the peaks linearly increased, whereas no reduction peak appeared. Under these conditions, a usable working range of $y=0.0761 \times-0.24$ and a precision of $R^{2}=0.9957$ for catechol and $y=0.0352 \times-0.1895$ and a precision of $R^{2}$ $=0.9972$ for caffeine were obtained. Catechol turned out to be two times more sensitive than caffeme. Under this condition. electrode comparisons were perfomed with the common-ty'pe glassy carbon and the non-treated $\mathrm{CN}$-type electrode. Figure l(b) shows the results. In the inset. the voltanmogram is the $130 \mathrm{mgL}^{-1}$ spike. In this condition, the glassy carbon electrode was obtained with a current of only $4.3 \times 10^{-6} \mathrm{~A}$ for caffeine and a peak of $0.01 \times 10^{-6} \mathrm{~A}$ for (a)

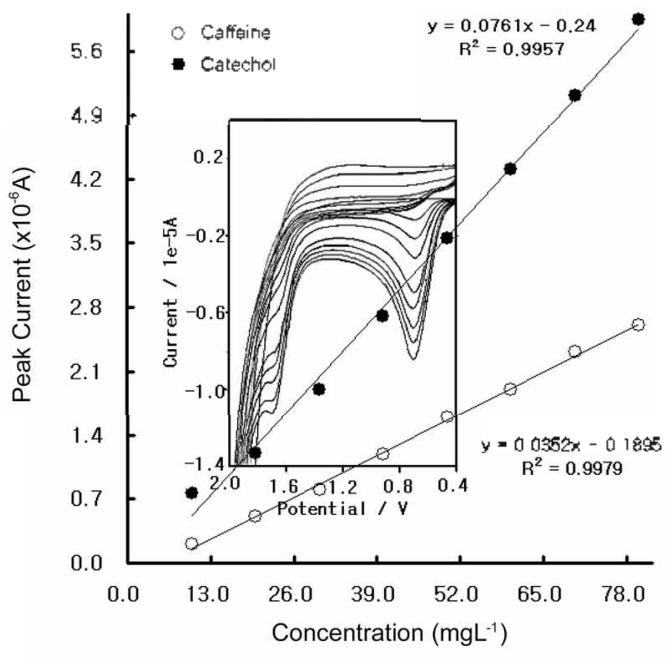

(b).
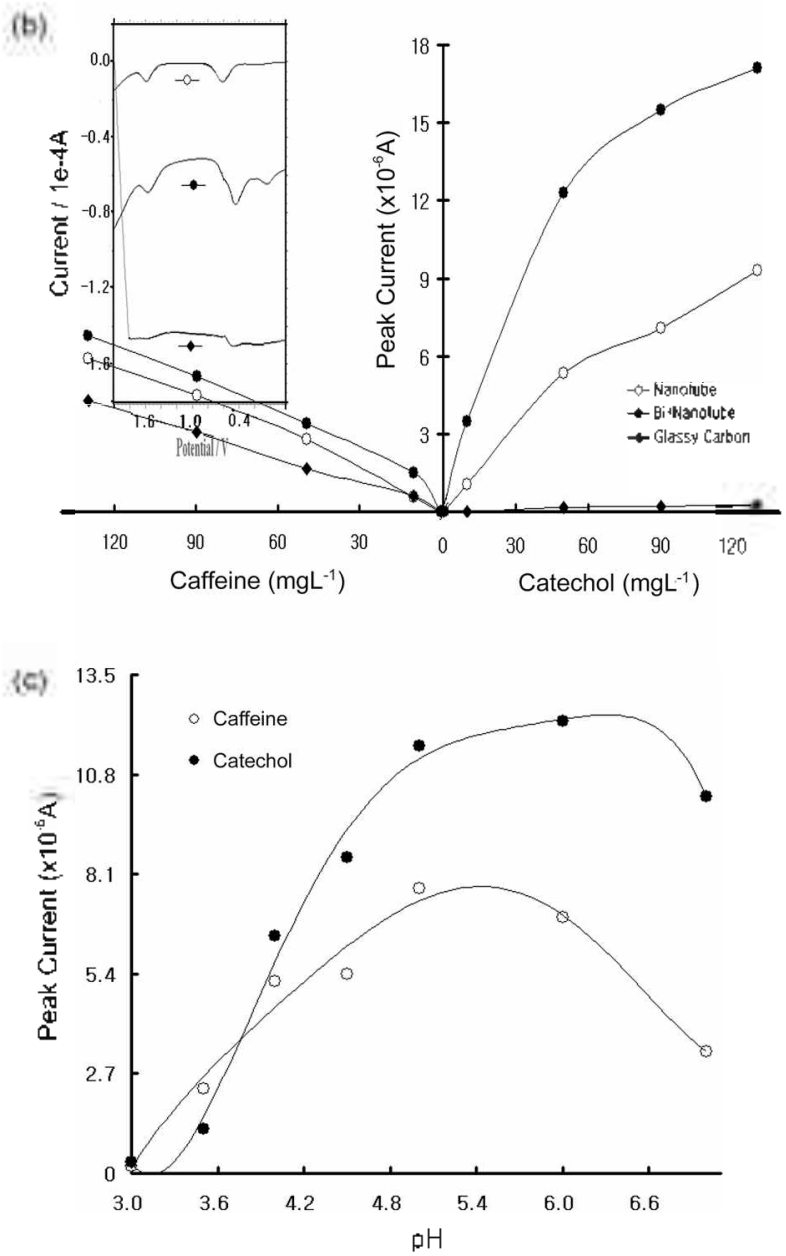

Figure 1. (a) Simultaneous variations for the 0-, 10-, 20-, 30-, 40-, $50-, 60-, 70$ - and $80 \mathrm{mgL}^{-1}$ caftieine and catechol spikes. The potentials were scanned between $0.0 \mathrm{~V}$ initial potential and $2.0 \mathrm{~V}$ switching potential with a scan rate of $3.5 \mathrm{~V} / \mathrm{s}$ for C $\mathrm{V}$ using glassy carbon electrode. (b) Electrode comparison of BPE, common-type $\mathrm{CN}$, and the glassy carbon electrode method in 0-, 10-, 50-, 90- and $130 \mathrm{mgL}^{-1}$ cafteine and catechol spikes. (c) Electrolyte $\mathrm{pH}$ variations of $3,3.5,4.0,4.5,5.0,6.0$ and $7.0 \mathrm{pH}$ using $\mathrm{BPE}$ and 80 $\mathrm{mgL}^{-1}$ catechol and cafteine spikes in a $0.1 \mathrm{M} \mathrm{H}_{3} \mathrm{PO}_{4}$ electrolyte solution. Other optimum parameters sere used. 
catechol. Also. the non-treated $\mathrm{CN}$ electrode showed a $5.9 \times$ $10^{-6} \mathrm{~A}$ caffeine peak and a $9.3 \times 10^{-6} \mathrm{~A}$ catechol peak. The $\mathrm{BPE}$ yielded a big $6.76 \times 10^{-6} \mathrm{~A}$ caffeine current and a 17.1 $\times 10^{-6} \mathrm{~A}$ catechol current. however, and was much more sensitive than the other two electrodes. Thus, more sensitive parameters were obtained with BPE. Figure l(c) shows the electroly te $\mathrm{pH}$ variations. The electroly te $\mathrm{pH}$ was controlled with the $0.1 \mathrm{M} \mathrm{HCl}$ and $0.1 \mathrm{M} \mathrm{NaOH}$ spikes to $\mathrm{pH} 5.0$, a peak current of $7.72 \times 10^{-6} \mathrm{~A}$ caffeine, a sensitive $11.57 \times$ $10^{-6} \mathrm{~A}$ catechol current, and a narrow peak. In these conditions, the SW stripping parameters were examined.

Optimization of BPE with Stripping Voltammetry. Figure 2(a) illustrates the stripping peak current in a 150 $\mathrm{mgL}^{-1}$ caffeine spike and a $70 \mathrm{mgL}^{-1}$ catechol spike for variation of the anodic accumulation potential. In this figure. catechol quickly decreased. but the peak width remained unaltered. On the other hand, the caffeine peaks continually and sharply increased. plus the optimum conditions were fixed at the $-0.6 \mathrm{~V}$ accumulation potential. where the peak heights of $2.997 \times 10^{-6} \mathrm{~A}$ for caffeine and $2.929 \times 10^{-6} \mathrm{~A}$ for catechol appeared. This manifested as the best condition. At this potential. the SW stripping voltammetric antiplitude variations were examined. Figure 2(b) shows the results at the $-0.6 \mathrm{~V}$ accumulation potential. Other conditions were set for the optimum parameters, and both peaks continually increased and yielded an optimum amplitude of $0.3 \mathrm{~V}$ for $4.03 \times 10^{-6} \mathrm{~A}$ caffeine and $43.8 \times 10^{-6} \mathrm{~A}$ catechol. The amplitude of the catechol peak current was 10 times bigger than that of the caffeine peak current. Figure $2(c)$ shows the resulting SW accumulation times. At $0-60 \mathrm{sec}$, the peak sensitively increased for $12.68 \times 10^{-6} \mathrm{~A}$ caffeine and $9.92 \times$ $10^{-6} \mathrm{~A}$ catechol. then decreased. Thus. the optimum conditions were $\mathrm{a}-0.6 \mathrm{~V}$ accunulation potential, a $0.3 \mathrm{~V}$ amplitude. and a $30 \mathrm{sec}$ accumulation time. Other parameters were fixed as in the conditions shown in Figure 3. Under these parameters. the analytical interference, working ranges, and in-vivo application were examined through stripping voltammetry.

Analytical Interference, Working Range, Statistics and in vivo Application. Under optimum conditions. the interference analogy ions were examined. Figure 3(a) shows the results. In the solutions with $20.0 \mathrm{mgL}^{-1}$ caffeine and catechol. other metal and neuro transmitter ions of [Cd(II). $\mathrm{Ca}(\mathrm{II}), \mathrm{Zn}(\mathrm{II}), \mathrm{Ba}$ (II), $\mathrm{Co}$ (II), $\mathrm{Cu}(\mathrm{II}), \mathrm{Ge}$ (IV), $\mathrm{Cr}$ (III), $\mathrm{Fe}(\mathrm{II})$. $\mathrm{Hg}(\mathrm{II}) . \mathrm{Ni}(\mathrm{III}), \mathrm{Ag}(\mathrm{I}), \mathrm{Pt}(\mathrm{IV})$. glycine dopanine, epineplrine. histidine and glucosel were spiked. the concentrations of which were all $200 \mathrm{mgL}^{-1}$. The caffeine peaks resulted in the following percentages: $-4.38 \%$. $-6.78 \% . \quad 10.27 \% .3 .49$ $\%,-35.55 \%,-53.27 \%,-25.23 \%, 26.52 \%,-19.90 \%,-17.63$ $\%,-13.76 \%, 12.4 \%,-26.82 \%, 64.74 \%, 5.05 \%, 12.22 \%$. $-10.89 \%$ and $3.70 \%$. The catechol peaks resulted in percentages as follows: $33.19 \%, 6.13 \%, 13.06 \%, 7.56 \%$. $5.13 \%,-6.87 \%, 0.09 \%,-17.54 \%, 16.38 \%, 4.90 \%,-21.76$ $\% .12 .64 \%, 134.0 \%, 30.35 \%, 16.43 \%, 45.88 \%, 14.35 \%$ and $5.07 \%$. Under these conditions. Pt and glycine strongly interfered. but other ions only weakly interfered. In Figure 3(b). the anodic working ranges were examined with
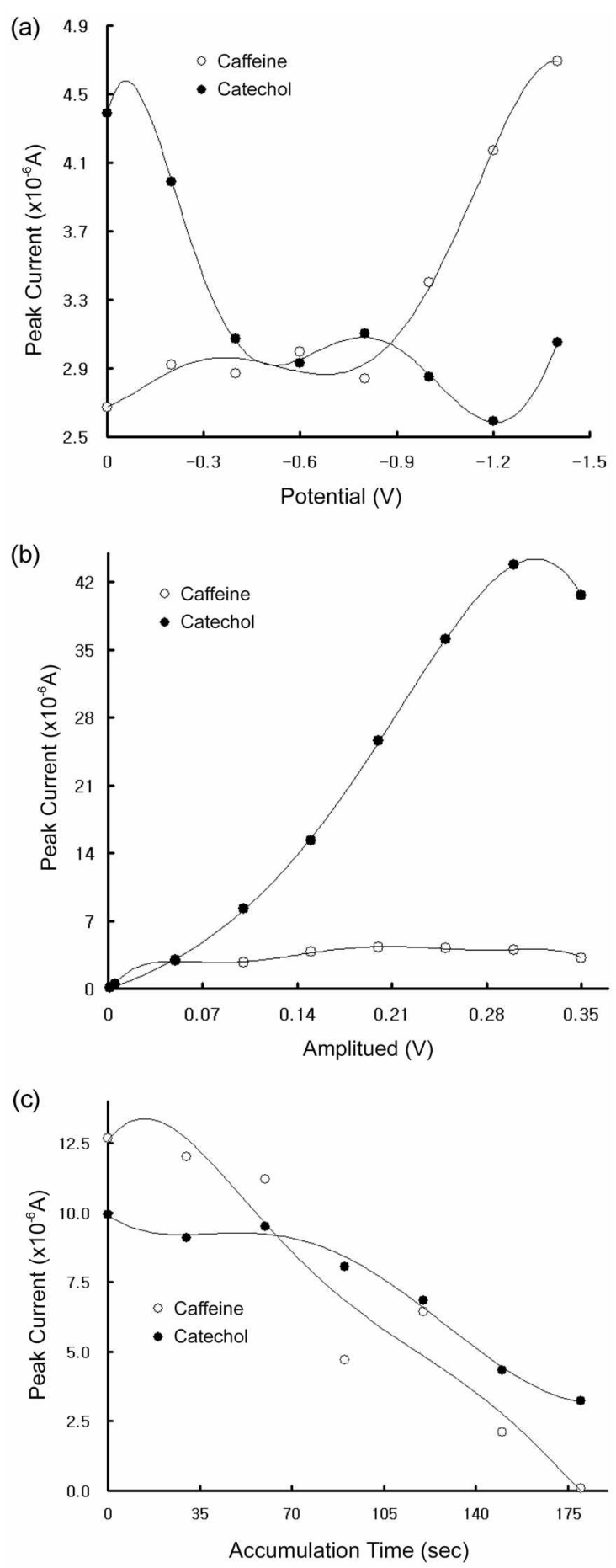

Figure 2. (a): Variations of $0 \sim-1.4 \mathrm{~V} \mathrm{SW}$ accumulation potentials (b): SW amplitude variations of $0.001 \mathrm{~V}-(0.35 \mathrm{~V}$. (c): Variations of $0-180 \mathrm{~s}$ SW accumulation time using a simultaneous $150 \mathrm{mgL} \mathrm{L}^{-1}$ cafteine and $70 \mathrm{mgL}^{-1}$ catechol spike in a $0.1 \mathrm{M} \mathrm{H}_{3} \mathrm{PO}_{4}$ electrolyte solution. Other parameters were fissed for the optimum conditions.

simultaneous spiking at a high concentration. Both peaks increased linearly the peak width was narrow and the sensitivity of caffeine was $\Delta \mathrm{v} / \Delta \mathrm{y}=6.7961$ and of catechol. $\Delta \mathrm{x} / \Delta \mathrm{y}=5.7313$. in which $\Delta \mathrm{x}=$ the catechol and caffeine concentration $\left(\mathrm{mgL}^{-1}\right)$ and $\Delta y=$ the peak current $\left(1.0 \times 10^{-6}\right.$ A). This working range is usable in any analytical assay. The 
results are applicable in pharmacy, but in vivo conditions require a variation of low detection limits. Thus, more sensitive working ranges were examined. At each electroly te cell. more sensitive conditions were obtained. Figure 3(c) shows the detection limits (DL) $(\mathrm{S} / \mathrm{N}=3)$ of $0.4 \mathrm{mgL}^{-1}$

(a)

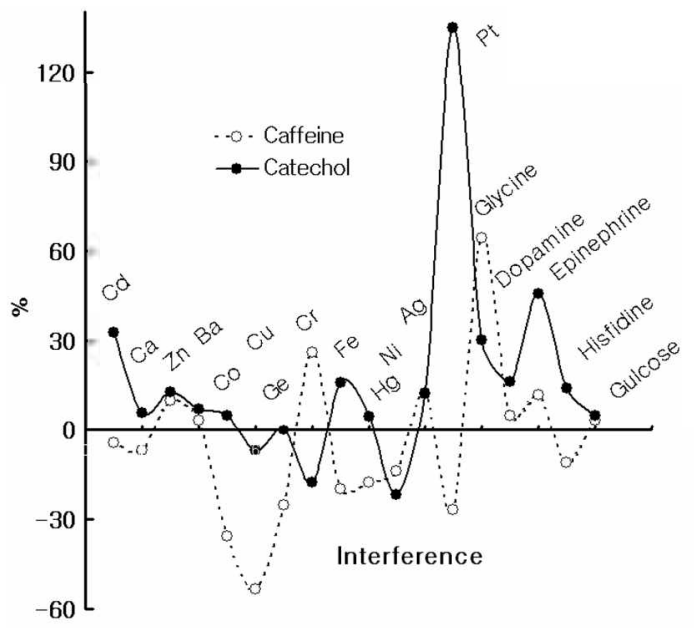

(b)

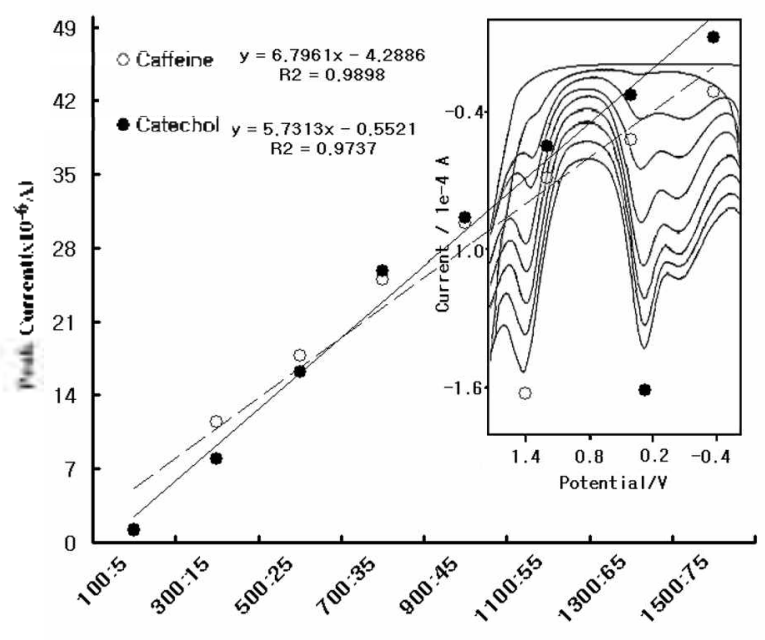

Concentration of Catechol and Caffeine $\left(\mathrm{mgL}^{-1}\right)$

(c)

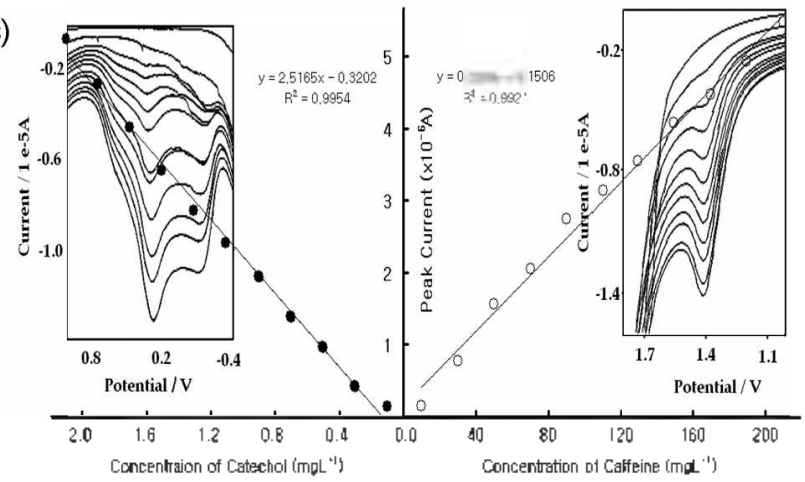

Figure 3. (A): Interference test. (B): High working range of 100:5$1,500: 75 \mathrm{mgL}^{-1}$ catfene and catechol at smultaneous addition. (C): Low working range of $10-210 \mathrm{mgL}^{-1}$ caffeme and another cell of the 0.1-2.1 mgL catechol spike, in a 0.1 $\mathrm{M} \mathrm{NH}_{4} \mathrm{H}_{2} \mathrm{PO}_{4}$ solution with a $\mathrm{pH}$ of $50, \mathrm{a}-0.6 \mathrm{~V}$ initial potential, a $0.3 \mathrm{~V}$ amplitude, a 40 $\mathrm{H} \angle$ frequency, a $0.003 \mathrm{~V}$ merement potential, and a 0 sec accumulation time. Optunum conditions were set for other parameters. caffeine and $0.06 \mathrm{mgL}^{-1}$ catechol. calculated as in Equation (1).

$$
\mathrm{DL}=k \mathrm{~s}_{\mathrm{P}} / b .
$$

in which DL is the detection limit. $k$ is a constant value of 3 according to IUPAC ( $\mathrm{S} / \mathrm{N}=$ signal noise ratio), $\mathrm{s}_{\mathrm{B}}$ is the standard deviation of the blank signals, and $b$ is the slop of the calibration plot. ${ }^{2 i j}$ Based on the calculation. catechol was 10 times more sensitive than caffeine. but their slop ratios were similar. These results are applicable in any living cell system. so a diagnostic application was performed in in vivo neuro conditions.

Analyses were carried out on the implanted in vivo fish brain and rat brain cells under real conditions. Under anesthetic conditions, the macro-type BPE was inserted deep $(7 \mathrm{~mm}$ ) into the fish's brain using a micro-hand drill. Then a $0.2 \mathrm{~mm}$-diameter wire-type platinum counter electrode and a $0.2 \mathrm{~mm}$-diameter chloride-coated $\mathrm{Ag} / \mathrm{AgCl}$ wire-type reference electrode were implanted into the fish's chest. All the cables were interfaced with the electrochemical workstation, and the open tissues were closed using a dental adhesive.

Using the same method. the rat implantation was performed. The fish specimen was transferred to a basin. In this bowl. $500 \mathrm{mgL}^{-1}$ caffeine and standard catechol were spiked. The next day. both ions were absorbed into the body system. Under living conditions. SW stripping was performed with a $-0.6 \mathrm{~V}$ accumulation potential. a $30 \mathrm{mV} \mathrm{SW}$ amplitude, a $40 \mathrm{~Hz} \mathrm{SW}$ frequency. a $3.0 \mathrm{mV}$ step potential,
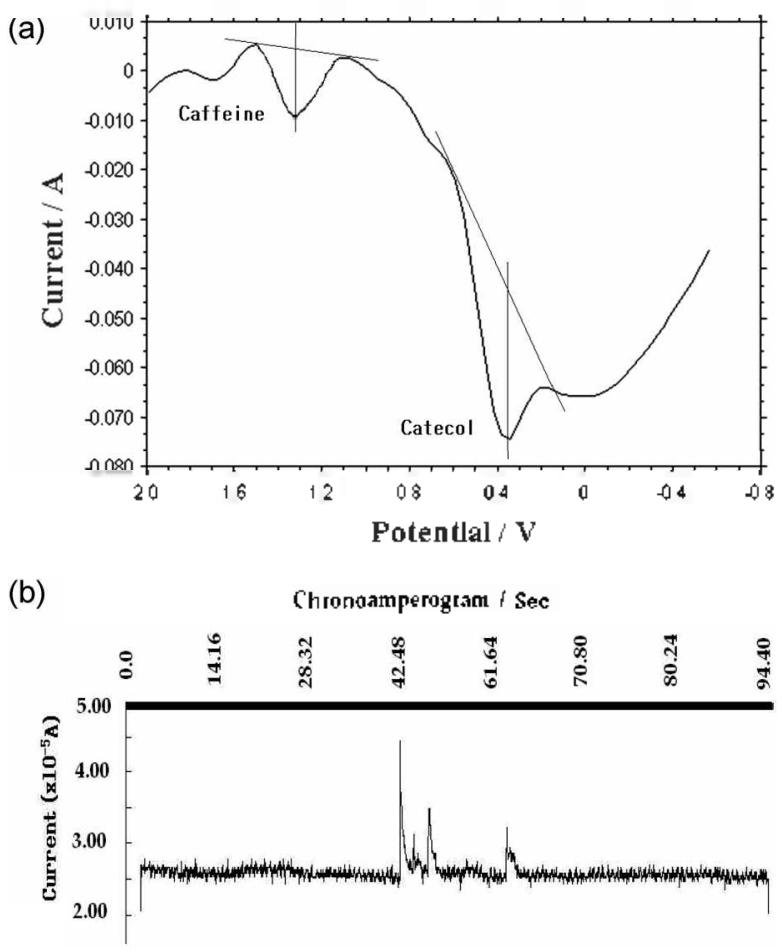

Figure 4. (A): SW stripping voltammograms of cafteme and catechol ions in $500 \mathrm{mgL}^{-1}$ cafteine and catechol contained in a bowl fish using BPE mplanted in a living tish bram. (B): Chronoamperometry using BPE mplanted in a living rat bram. Other parameters were used for optimum conditions. 
and a 30 seconds accunulation time. Figure $t$ (a) shows the two peaks with a $1.25 \times 10^{-2} \mathrm{~A}$ peak height at $1.3 \mathrm{~V}$ for caffeine and with a $2.369 \times 10^{-2} \mathrm{~A}$ peak height at $0.4 \mathrm{~V}$ for catechol (for healthy humans and rats plasnia the standard is $375 \pm 57 \mathrm{pgmL}^{-1}$. $\left.475 \pm 52 \mathrm{pgmL}^{-1}\right)$. $^{31}$ Thus. they can be assayed directly in wo $\left(1.78 \sim 2.90 \times 10^{-8} \mathrm{molL}^{-1}\right.$ in rat brain), ${ }^{32}$ and can be used for neural diagnosis and medicinal treatment. More advanced methods were performed in the rat brain with the implanted BPE macro-sensor. In the interfacing circuits. $0.4 \mathrm{~V}$ was applied to catechol, and chronoamperometry was performed. Figure $4(b)$ shows the resulting physiological current. Within $0-350 \mathrm{sec}$, the rat was not moved and only slight noise signals were obtained. Within $410-455$ and 570 sec. a plysiological impulse was supplied to the rat body skin using a bristle tip, producing a sensitive sharp current and a repeated identical peak current under the same conditions. Thus, physiological neural signals (EEG: electroencephalogram) $)^{33}$ can be detected, and the methods presented in this study can be applied to brain diagnosis, ${ }^{34}$ neural contro. ${ }^{356}$ and $i n$ wivo signal. ${ }^{37}$

\section{Conclusion}

A low catechol and caffeine concentration was assayed using a voltammetric BPE sensor. The optimum SW conditions were found to be as follows: $0.3 \mathrm{~V}$ amplitude, $40 \mathrm{~Hz}$ frequency, $-0.6 \mathrm{~V}$ accumulation potential, $3 \mathrm{mV}$ increment potential, $30 \mathrm{sec}$ deposition time. and $5.0 \mathrm{pH}$ electrolyte strength. The method was shown to be more sensitive than the previous $\mathrm{DL}^{S-1 \geq 10.230^{\circ}}$ and could be attained at low working ranges for in wivo diagnosis. Tree electrode systemis can be implanted into the fish and rat brain cell. In this circuit. physiological neuro-currents were obtained in real time as well as in in wo conditions. The method can also be applied to pharnaceuticals and in vivo drugs in addition to in vitro monitoring.

\section{References}

1. Strong. R.: Grotta. J. C.: Aronowski. J. Neuropharmacologr 2000. 39.522 .

2. Wei. P. W. Jing. X. H.: Bertil. B. F.: Zsuzsanna. W. H.: Xiao. J. X. Netwosci. Lett 2006. 402,164

3. Jelenka. N.: Gordana. B.: Ivana. S. Mol. Cell Biochem. 2003. 2t4. 125 .

4. Mamoru. T.: Takeshi. O.: Hirovuki. H.: Chieko. K.: Toshiyuki. O.: Tadashi. U.: Takeshi. U.: Nobumasa. K.: Tsukasa. S. Nemrosci. Res. 2006. $5 \% 180$.

5. Makoto, T: Kazuko, T: Mayunini. M: Kazuhiro. 1. Biomed.
Chromatogr: 2002. 16.536.

6. Nozomi. A.: Makoto. T.: Kazuya. N.: Kazuhiro. 1. Bionted. Chrematogr: 2002. 16.255.

7. Jun. U.; Kiyoyuki, I.: Mitsunori, I.: Kenji, T.: Kenzo, T.: Takaaki. H. J. Chomatog: $B$ 2003, 798,35 .

8. Koch. J. P.: Tusscher, G. W: Koppe, J. G: Guchelaar, H. J. Bionted Chronatogr 1999. 13. 369.

9. Fiona. R.: Yuliya. S. Anal Chimt Acta 2005. 5+0. 103.

10. Qian. L. Z.: Hong. Z. L.: Wei. H. W.: Hong. Y. C. J. Chromatogr: A 2005, 1098. 172 .

11. Sergio, A.: Salvador. G.: Miguel. G. Anal. Chim. Acta $2005,547$. 197.

12. Koch. J. P.: Tusscher. G. W: Koppe. T. G: Guchelaar. H. T. Bionted Chontatogr: 1999. 13. 3069

13. Renata. S. P.: Luis. A. P. F.: Tairo. K. B. J. Sep. Sci. 2002.25. 371 .

14. Kaname. 0.; Mitsuhiro. W.: Gwyn, A. L.; Yoshihito, O:- Mihoko. N. N.: Kenichiro. N.; Shuzo. A.; Chang. K. L.; Naotaka. K. Electrophoresis 2005. 26.812.

15. Gulab. N. T.: Sergio. A. F. Phwochent. Anal. 2002. 13. 99.

16. Sergei. S. V: Christopher. J. L.: Asit. M. J. Chrontatogr A 2006. 1116,193 .

17. Nathan, W: Kenneth, M. J. Phamaceut. Biomed 2005. 37,669.

18. Russell, H. R; Jane, E. G. Rapid Commun. Mass Sp. 1997. 11. 1661 .

19. Rongguo. S.: Jin. M. L.: Feng. Q.: Zhifeng. C.: Yuthua. G.: Masaaki. Y. Analytica Chinica Act. 2004. 508.11

20. Gamze. E.: Ersin. K. A. Talanta 1997. H, 2011.

21. Marazuela, M.; Agui, L.; Gonzalez. C. A.: Yanez. S. P: Pingarron. J. M. Electroanal. 1999. $11(1), 1333$.

22. Michael. W. D.: Mark. E. M. Electromal 1998. 10. 157

23. Suw: Y. L.: Yun. K. K. Sensor Actuat A-phns. 2006. 127. 41

24. Suw. Y. L.: Sung. K. K.: Tae. H. K.: Young. S. J.: Sang. M. L. J. Appl. Electochem. 2005, 35. 567.

25. Nicolae, S.: Bulusu. V. S.; Donald, A. T.: Akira. F. Electronal 2002. 14.721

26. Andrea. P.: Jozef. S.: Miroslav. S.: Stanislav. M. J. Sci. Food.dgr 1999. 79. 1136.

27. Suw. Y. L. Bioelectrochemismy 2005. 68. 232

28. Joseph, W.: Jianmin. L.: Samo. B. H; Percio. A. M. F. Anal. Chem. $2000,72,3218$.

29. Suw. Y. L. Bull. Korean Chem Soc. 2006, 27, 1613.

30. Sonia. M. S. Electromalysis 1998. 10.722.

31. Jun. U.: Kiyoyuki. K.: Mitsunori. I.: Kenji. T.: Kenzo. T.: Takaaki. H. J. Chontatogr: $B$ 2003. 798. 35 .

32. Song. Z.: Qun, X:, Wen, Z; Litong, J: Ji. Y. J. Anal. Chim Acta 2001. 427,45

33. Robert A.: David. S. Artif. Intell .Hed 2001. 21. 185

34. Suw. Y. L. Talamta 2008. 7t. 1635.

35. Adams. C.: Mathieson. K.: Gurnuing. D.: Cuntringham1. W.: Rahtrnan. M.: Morrison. I. D.: Prydderch. M. L. Nicl Howntm. Heth. A 2005. $5+6,154$.

36. Keekeun, L.: Amarjit, S: Jiping. H: Stephen. M.: Bruce. K: Gregon, R. Sensor Actuat B Chem. 2004. 102,67.

37. Karen. C. C.: Plilippe. R.: Heikki. T.: Kaj. D. Biosens Bioelectron. 2007. 22. 1783. 